\title{
Temperature Compensation Circuit for ISFET Sensor
}

\author{
Ahmed Gaddour $1,2, * \mathbb{C}$, Wael Dghais ${ }^{2,3}$, Belgacem Hamdi ${ }^{2,3}$ and Mounir Ben Ali ${ }^{3,4}$ \\ 1 National Engineering School of Monastir (ENIM), University of Monastir, Monastir 5000, Tunisia \\ 2 Electronics and Microelectronics Laboratory, LR99ES30, Faculty of Sciences of Monastir, \\ University of Monastir, Monastir 5000, Tunisia; wael.dghais@hotmail.co.uk (W.D.); \\ belgacem.hamdi@gmail.com (B.H.) \\ 3 Higher Institute of Applied Sciences and Technology of Sousse (ISSATSo), University of Sousse, \\ Sousse 4003, Tunisia; mounirbenali@yahoo.com \\ 4 Nanomaterials, Microsystems for Health, Environment and Energy Laboratory, LR16CRMN01, \\ Centre for Research on Microelectronics and Nanotechnology, Sousse 4034, Tunisia \\ * Correspondence: gaddourahmed@yahoo.com; Tel.: +216-50998008
}

Received: 3 November 2019; Accepted: 21 December 2019; Published: 4 January 2020

check for updates

\begin{abstract}
PH measurements are widely used in agriculture, biomedical engineering, the food industry, environmental studies, etc. Several healthcare and biomedical research studies have reported that all aqueous samples have their $\mathrm{pH}$ tested at some point in their lifecycle for evaluation of the diagnosis of diseases or susceptibility, wound healing, cellular internalization, etc. The ion-sensitive field effect transistor (ISFET) is capable of $\mathrm{pH}$ measurements. Such use of the ISFET has become popular, as it allows sensing, preprocessing, and computational circuitry to be encapsulated on a single chip, enabling miniaturization and portability. However, the extracted data from the sensor have been affected by the variation of the temperature. This paper presents a new integrated circuit that can enhance the immunity of ion-sensitive field effect transistors (ISFET) against the temperature. To achieve this purpose, the considered ISFET macro model is analyzed and validated with experimental data. Moreover, we investigate the temperature dependency on the voltage-current $(\mathrm{I}-\mathrm{V})$. Accordingly, an improved conditioning circuit is designed in order to reduce the temperature sensitivity on the measured $\mathrm{pH}$ values of the ISFET sensor. The numerical validation results show that the developed solution accurately compensates the temperature variation on the measured $\mathrm{pH}$ values at low power consumption.
\end{abstract}

Keywords: ISFET sensor; conditioning circuit; temperature compensation; overall sensitivity

\section{Introduction}

The ion-sensitive field-effect transistors (ISFETs) sensor has played a major role in enabling the fabrication of fully integrated CMOS-based chemical sensing systems. This has allowed several new application areas, with the most promising fields being ion imaging and full genome sequencing. However, the data from this sensor is strongly affected by the variation of the temperature. ISFET is a chemical sensitive microsensor that is based on the field effect transistor, which was invented by Bergveld in the 1970s [1].

The detection principle (shown in Figure 1) of the ISFET sensor mechanism is centered on the charge adsorption at the solid ion interface between the electrolyte and the layer that contains the hydroxyl groups [2]. The assembly of hydroxyls can give or accept a proton. As a result of this process, a double layer capacity is generated with a potential variation that in its turn has an impact on the threshold voltage of the transistor according to the $\mathrm{H}+$ ion concentration (i.e., $\mathrm{pH}$ ) [2]. Moreover, ISFET is a compact sensor that enables a fast $\mathrm{pH}$ measurement. 


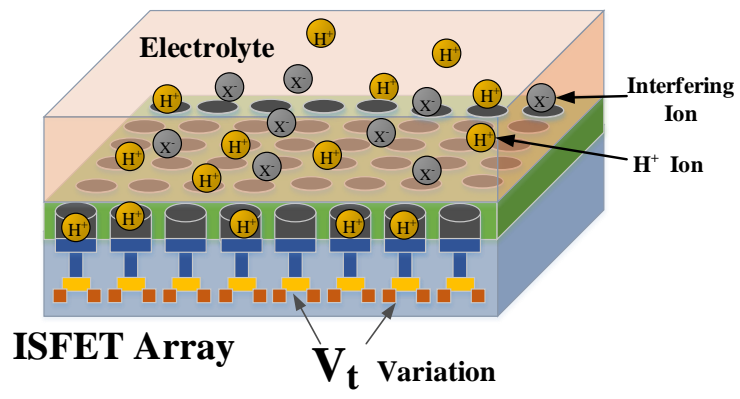

Figure 1. 3D representation of a $6 \times 8$ ion-sensitive field effect transistor (ISFET) array.

However, this type of sensor is strongly affected by the temperature variation. Therefore, several researchers [3-7] have proposed various temperature compensation systems such as the proper choice of a biasing current for a thermal working point to reduce the ISFET's temperature dependency [4]. Hence, the use of a junction diode Zener [4] for temperature compensation on a single ISFET sensor, the employment of an ISFET with a differential configuration (use of a differential amplifier) [8] that increases the immunity against temperature variation, or the combination of attenuators and a differential amplifier alongside with Caprio's quad [7] were used in order to enhance the temperature stability. The trend of the recent works is set on ISFET sensor arrays [9-13], but most of these researches are focused on the wearable and thermoelectrically powered system [11] and on achieving very high accuracy and a small settling time [10]. They also focused on system-on-chip for real-time ion imaging [13], but most of them did not focus on the temperature effect on the response of the sensor and did not give a robust solution to reduce it. From these approaches, it can be noticed that the temperature dependency is studied at a particular or in a narrow range.

For a wide range of $\mathrm{pH}$ values, the temperature compensation becomes more difficult, since the temperature's coefficient of an electrochemical device is a function of the $\mathrm{pH}$ value [14]. Moreover, the ISFET's temperature dependency tends to exhibit a random behavior [15-17]. The straight-line-based temperature compensation limits its scope when dealing with the actual nonlinear temperature characteristic of ISFET's device at different values. Furthermore, the temperature dependency of measuring a circuit also introduces additional temperature influence on the measured data. As a result, the ease of combining the temperature compensation circuit, the efficiency of the compensation technique, the circuit sensitivity, as well as the circuit simplicity with respect to body effects became the key design considerations in an integrated circuit design. Respectively, it is particularly challenging for ISFETs to work in an environment where the required task is to measure different $\mathrm{pH}$ ranges alongside different temperature values [18,19]. Nevertheless, the conventional means used in the signal processing of ISFETs, in particular the elementary current-voltage conversion circuits, do not reach optimal performance since they are sensitive to light variations and temperature especially when we use a sensor array (spread of the error that is related to temperature). In this study, it is important to understand the temperature behavior of an ISFET from a foundation work alongside research of a robust ISFET interface circuit combined with an improved temperature compensation technique. In view of the above problems, an improved ISFET interface circuit with a simple structure is proposed. This is in conjunction with the investigation of an improved dynamic biasing temperature compensation method. The latter is concerned with the arrangement of numerical iteration and mutual compensation in ISFET's MOS transconductance characteristics. This results in almost zero temperature coefficients at any $\mathrm{pH}$ value. This enables the ISFET's interface circuit to measure simultaneously the correct values of $\mathrm{pH}$ at any temperature. In this work, we investigate the temperature's influence on the ISFET. Then, we propose a new integrated circuit, which is capable of reducing the temperature dependency and is applicable for systems such as sensor arrays. Then, we present a new demonstration of temperature compensation using the differential setup. Many researchers have reported several ISFET/reference field effect transistor (ReFET) topologies [20-25], and the first circuit that used ISFET/ReFET was introduced by Bergveld [20]. In this work, we present a new circuit based on 
differential measurement (ISFET/ReFET) operating in a weak inversion regime, and we demonstrate with a simple manner (mathematically) the temperature compensation using the ISFET/ReFET topology.

This paper is organized as follows. Section 2 presents the conventional ISFET macro model, Section 3 investigates the temperature's effect on the validated ISFET model, Section 4 illustrates a new conditioning circuit for temperature compensation, and Section 5 concludes the paper.

\section{ISFET Macro Model}

The considered ISFET macro model that captures the ISFET sensor current voltage (I-V) characteristic behavior is under temperature variation and based on the model developed under PSPICE $[26,27]$. The ISFET response to the $H^{+}$ion is demonstrated by site binding theory, which gives a complete description of the ISFET behavior when combined with the Gouy-Chapman-Stern model and MOSFET physics [26]. As a consequence, a set of equations has been drawn up in order to study the sensitivity of the sensor and its dependence according to the physicochemical parameters of the ISFET. Subsequently, the SPICE macro model considers the ISFET sensor as two uncoupled stages: an electrochemical stage that represents the interface electrolyte-insulator modeled by site binding theory, along with an electronic stage, which is modeled by MOSFET. The considered equivalent electrical circuit of the ISFET macro model is shown in Figure 2.

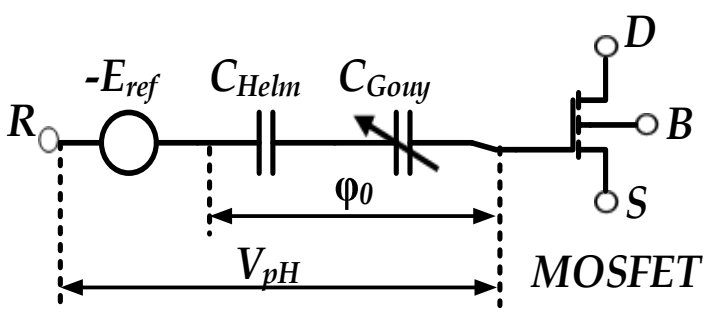

Figure 2. Equivalent electrical circuit of the ISFET structure.

Where $\mathrm{R}$ is the reference electrode, $\mathrm{D}$ is the drain, $\mathrm{S}$ is the electrolyte-insulation source, $\mathrm{B}$ is the substrate, and $V_{p H}$ refers to the potential of the electrolyte-insulation interface. The expression of $V_{p H}$ can be written as follows:

$$
\begin{gathered}
V_{p H}=-E_{r e f}+\varphi_{0} \\
\varphi_{0}=2.3 \frac{K T}{q} \alpha\left(p H_{p z c}-p H\right)
\end{gathered}
$$

where $E_{r e f}$ is the potential applied to the reference electrode, $\varphi_{0}$ is the electrostatic potential, which is directly proportional to $\mathrm{pH}$ and temperature, $K$ is the Boltzmann constant, $T$ is the absolute temperature, $p H_{p z c}$ is the $\mathrm{pH}$-zero point of charge, $q$ is the electron charge, and $\alpha$ is the corrective parameter for $\mathrm{pH}-\mathrm{ISFET}$, which ranges between 0 and 1 . The electrochemical properties of the insulating surface were combined with the nonlinear current-voltage (I-V) MOSFET, resulting in an expression of the threshold voltage of the ISFET, including terms derived from the MOSFET theory as well as terms of an electrochemical nature [26]:

$$
\begin{gathered}
V_{t_{I}}(\text { ISFET })=\left(E_{r e f}+\varphi_{l j}\right)-\left(\varphi_{0}-\chi_{e}\right)-\left[\frac{Q_{s s}+Q_{s c}}{C_{o x}}-2 \varphi_{f}+\frac{\varphi_{s c}}{q}\right] \\
V_{t_{I}}(I S F E T)=V_{t_{M}}(\text { MOSFET })+E_{r e f}+\varphi_{l j}+\chi_{e}-\varphi_{0}-\frac{\varphi_{m}}{q}
\end{gathered}
$$

where $\varphi_{f}$ is the fermi potential of a semiconductor, $Q_{s s}$ is the charge density per surface unit at the insulator/semiconductor interface, $Q_{s c}$ is the charge density in the semiconductor depletion region, $\varphi_{l j}$ is the tension between the reference solution and the electrolyte, $C_{o x}$ is the gate oxide capacity, and $\chi_{e}$ is the interface potential electrolyte/insulator dipole. It is worth noting that the potential $\varphi_{0}$ 
is the only variable that depends on $\mathrm{pH}$. Considering the weak inversion region of MOSFET, the I-V characteristic of ISFET can be written as follows:

$$
I_{d s}=I_{0} e^{\left(\frac{V_{g s}-V_{t}}{\eta U_{t}}\right)}
$$

where $I_{0}$ is a characteristic current, $U_{t}$ is the thermal voltage, and $\eta$ is the slope factor of the subthreshold. This mode of operation offers an opportunity to have a high intrinsic voltage gain and a low power processing.

\subsection{Fabrication and Testing}

The N-channel ISFET fabrication was carried out at the Semiconductor Physics Department, Research Institute of Microdevices (Kyiv, Ukraine). The gate dielectric is based on a $S_{\mathrm{iO}_{2}} / S_{i 3} N_{4}$ sensitive film structure [28]. The sensor chip was attached to a Sital (fused silica) support and was bound to the aluminum conductors. The length of the canal is about $7 \mu \mathrm{m}$, and its width is $250 \mu \mathrm{m}$. To measure the current voltage $\left(I_{d s}\right)$ characteristics of the ISFET, the substrate and the source are grounded and the source-drain voltage $\left(V_{d s}\right)$ was maintained at $1 \mathrm{~V}$. To measure the sensitivity of the ISFET sensor, we used three buffer solutions from $\mathrm{pH}=3$ to $\mathrm{pH}=11$. To investigate the reliability and stability of the $\mathrm{pH}$ sensor, we evaluated the temperature effects on the responses of the ISFET. Temperature can affect the characteristics of a sensor, the $\mathrm{pH}$ of the electrolyte, the potential of a reference electrode, and the measuring system. For latter changes, the temperature was kept constant inside the room. To keep the electrolyte, electrode, and ISFET at constant temperature, a heat-regulating loop including a temperature-sensing system and a heating system have been used. In addition, experimental results can only be compared validly to theory if the temperature during measurements is fixed. Figure 3 shows the experimental setup and the simulated equivalent circuit model implemented in the ADS based on modified SPICE model.
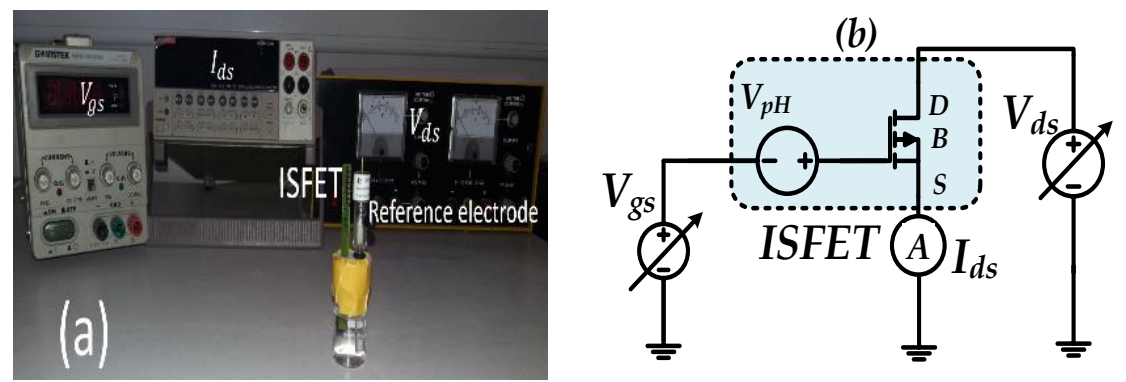

Figure 3. (a) Experimental setup using the ISFET sensor, (b) ADS circuit simulation using the ISFET model.

For the experimental setup, we used a GW Instek SPS-606 generation for the $V_{g s}$ variation; for measuring the $I_{d s}$ variation, we used a Keithley 2400 Source Meter, and for $V_{d s}$, we used a simple DC generator. The results extracted from the simulation of the macro model were compared with the experimental recorded data, as shown in Figure 4.

The good agreement between the experimental and simulated data is confirmed by estimating Error (6), which is about $1.12 \%$ (worst case) for $\mathrm{pH}=11.01 V_{g^{s}} \in[-1.8 \mathrm{~V},-0.5 \mathrm{~V}]$. For the next parts of this work, we used the validated macro model.

$$
\varepsilon(\%)=\sum_{i=1}^{n=8}\left(\frac{I_{s_{\text {exp }}}-I_{d s_{\text {model }}}}{I_{d s_{\text {exp }}}}\right) \times 100
$$

Moreover, Table 1 reports the technological parameters used for the ISFET macro model. 

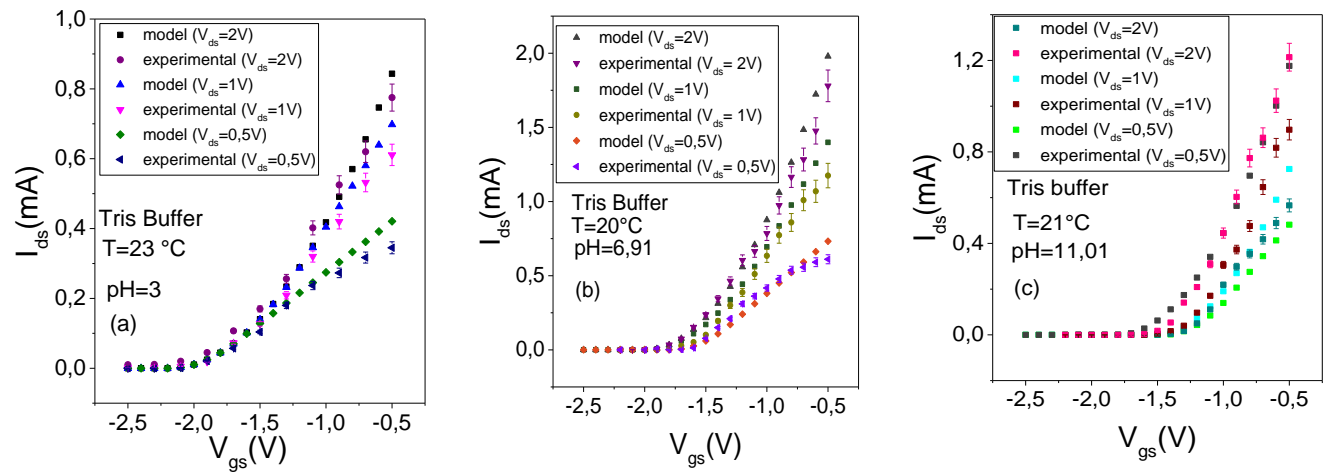

Figure 4. Model simulated in ADS versus experimental data.

Table 1. Technological parameters of the simulated macro model.

\begin{tabular}{cc}
\hline Parameters & Values \\
\hline$V_{t o}:$ Threshold Voltage $(\mathrm{V})$ & -1.7 \\
$\varphi_{0}:$ Surface Potential $(\mathrm{mV})$ & 555 \\
$\lambda_{0}:$ Channel length $(\mu \mathrm{m})$ & 7.59 \\
$C_{j}:$ Junction Capacity $\left(\mathrm{F} / \mathrm{cm}^{2}\right)$ & 4.44 \\
$C_{j s w}:$ Junction Sidewall Capacity $(\mathrm{pF} / \mathrm{m})$ & 515 \\
$T_{o x}:$ oxide thickness $(\mathrm{nm})$ & 150 \\
\hline
\end{tabular}

\subsection{Sensor Sensitivity}

In order to estimate the sensitivity of validated macro model, Figure 5 shows the variations of $\partial\left(\log \left(I_{d s}\right)\right) / \partial V_{g s}$ as a function of $V_{g s}$ at constant $V_{d s}=1 \mathrm{~V}$. The threshold voltage extraction method present in Figure 5 is inspired from the second derivative method [29], unless this technique can provide an exact threshold value more accurately. The proposed method enables other perspectives for the extraction of the technological parameters of the transistor.

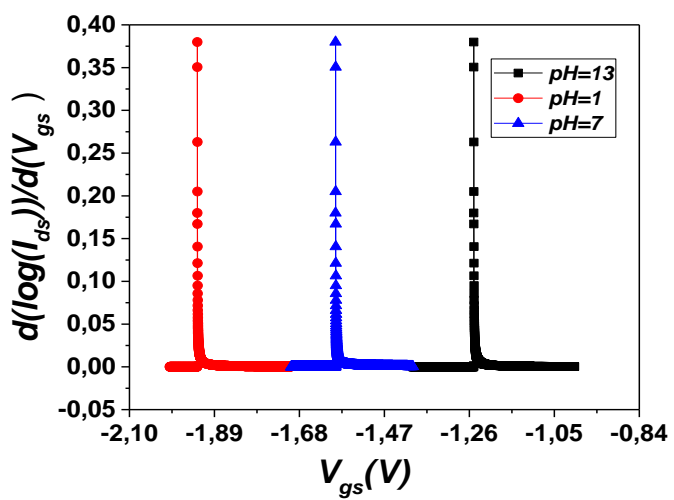

Figure 5. $\partial\left(\log \left(I_{d s}\right)\right) / \partial V_{g s}=f\left(V_{g s}, P H_{i}\right)$ characteristics for different values of $p H \in\{1,7,13\}$ at $\mathrm{T}=27^{\circ} \mathrm{C}$.

The $V_{t I}$ is extracted for different $\mathrm{pH}$ values using the method of the first derivation. These values are then plotted on a graph as a function of the $\mathrm{pH}$.

As seen in Figure 6, the determined sensitivity based on the ISFET macro model simulation (i.e., $s_{m}=54 \mathrm{mV} / \mathrm{pH}$ ) has approximately the same the sensitivity, which was calculated based on the experimental data (i.e., $s_{\exp } \approx 51 \mathrm{mV} / \mathrm{pH}$ ). In fact, the experimental ISFET characteristics were validated against the implemented macro model in order to accurately predict the $\mathrm{pH}$ values. 


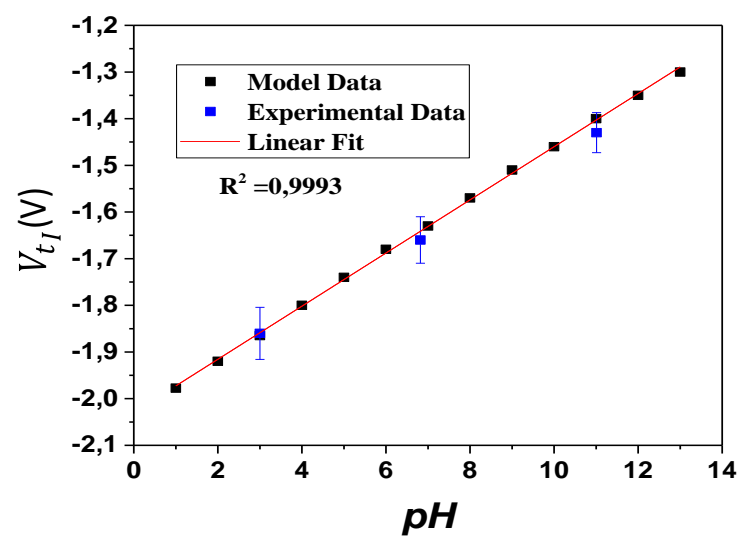

Figure 6. Variation of $V_{t_{I}}$ of the sensor as a function of the $\mathrm{pH}$ (model and experimental data).

\section{ISFET Temperature-Dependent Behavior}

Several works have demonstrated that the ISFET electrochemical behavior shows a temperature dependency. In fact, the temperature variation affects the ISFET sensing circuit such as the reference electrode, electrolyte insulator potential, and MOSFET transistor. It can be expressed as:

$$
T_{C_{T}}=T_{C_{R}}+T_{C_{I}}+T_{C_{F}}
$$

where $T_{C_{T}}$ refers to the total temperature coefficient of ISFET. $T_{C_{R}}$ is the temperature coefficient of reference electrode $E_{r e f}$, which has been reported by [22] with a standard value about $0.14 \mathrm{mV} /{ }^{\circ} \mathrm{C}$. $T_{C_{I}}$ refers to the temperature coefficient of the interface potential electrolyte insulator. It has also been proven that $T_{C_{I}}$ is a function of $\mathrm{pH}$ value. It can differ from $0.54 \mathrm{mV}$ to $1.1 \mathrm{mV}$ as the $\mathrm{pH}$ increases from 4 to 10 [30]. The third item in (7) $T_{C_{F}}$ represents the coefficient of the temperature in MOS structure of ISFET. Based on the device physics, the principal parameters that are responsible for the temperature dependency of the MOSFET transistor are the mobility and threshold voltage. For any temperature, it can be modeled as follows:

$$
\begin{gathered}
\mu(T)=\mu\left(T_{0}\right)\left(\frac{T}{T_{0}}\right)^{-n} \\
V_{t_{M}}(T)=V_{t_{M}}\left(T_{0}\right)+K_{V T}\left(T-T_{0}\right)
\end{gathered}
$$

where $T_{0}$ is the reference temperature and $n$ is a constant, with standard values between -1.9 and -2.2 , depending on the doping concentrations of silicon. $K_{V T}$ refers to the temperature coefficient of the threshold voltage, which is usually between $-0.5 \mathrm{mV} /{ }^{\circ} \mathrm{C}$ and $-3 \mathrm{mV} /{ }^{\circ} \mathrm{C}$.

\section{Analysis of the Temperature Effect on the ISFET Sensor}

Studies by Jung-Lung CHIANG et al. [31] have shown that ISFET has a high temperature dependency, which leads to a $\mathrm{pH}$ measurement inaccuracy, so it is very important to study the temperature behavior of ISFETs and determine relevant methods to improve their temperature stability.

It is worth noting that by analyzing Figure 7 , the drain current $I_{d s}$ of the ISFET macro model varies considerably with the temperature. It deteriorates with an increase in temperature. This behavior is dominated by two phenomena: the degradation of the mobility $\mu$ and the shift of the threshold voltage $V_{t_{M}}$, which result in the offset of the gate-source voltage $V_{g s}$ below and above the isothermal point, respectively.

For $V_{g s} \in[-2 \mathrm{~V},-0.75 \mathrm{~V}]$, we notice an offset of the threshold voltage $V_{t_{I}}$ above the isothermal point, which results in an increase of this later when the temperature increases.

For $V_{g^{s}} \in[-0.75 \mathrm{~V}, 0.5 \mathrm{~V}]$, the degradation of the mobility $\mu$ is observed underneath the isothermal point. In fact, the temperature dependence of of the mobility significantly increases with the temperature [32]. 


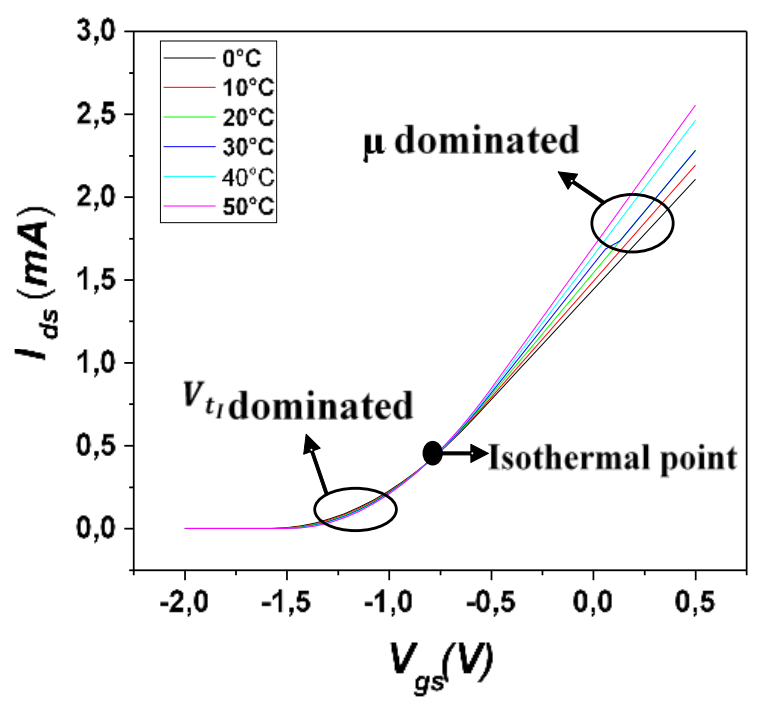

Figure 7. $I_{d s}=f\left(V_{g s}, V_{d s}=1 \mathrm{~V}\right)$ curves of the ISFET sensor at temperatures between 0 and $50{ }^{\circ} \mathrm{C}$.

The curvatures of Figure 8 are almost similar to the plots of Figure 7, but the only difference is shown by the dislocation of the isothermal point for the $\mathrm{pH}$ values equal to 3 and 8 (both Figures 7 and 8 are obtained from the simulation of ISFET macro model). The dislocation of the isothermal point causes a decrease of the drain-source current $I_{d s}$ and an increase of the gate source voltage $V_{g s}$.

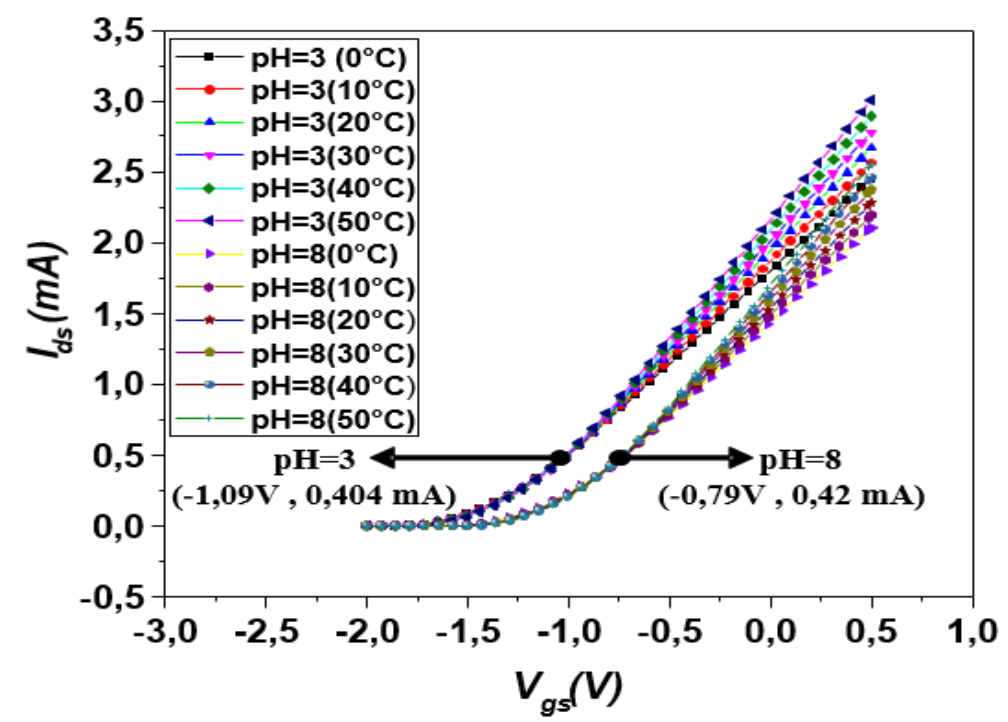

Figure 8. $\left(V_{g s}\right)$ curves of the ISFET sensor at a temperature between 0 and $50{ }^{\circ} \mathrm{C}$ with a step of $10{ }^{\circ} \mathrm{C}$ for $\mathrm{pH}=3$ and 8 .

Figure 9 demonstrates the variation of the threshold voltage as a function of $\mathrm{pH}$ over a wide temperature range. The shifting of the threshold voltage also results in the degradation of the sensor sensitivity for high $\mathrm{pH}$ values when the temperature varies from 0 to $50^{\circ} \mathrm{C}$. From visual inspection, the sensitivity of the sensor linearly varies with respect to the temperature, which is reported in Table 2.

Table 2. Variation of the sensor's sensitivity according to the temperature's variation.

\begin{tabular}{ccccccc}
\hline $\mathrm{T}\left({ }^{\circ} \mathrm{C}\right)$ & 0 & 10 & 20 & 30 & 40 & 50 \\
\hline Sensitivity $(\mathrm{mV} / \mathrm{pH})$ & 63 & 58 & 54 & 51 & 40 & 38 \\
\hline
\end{tabular}




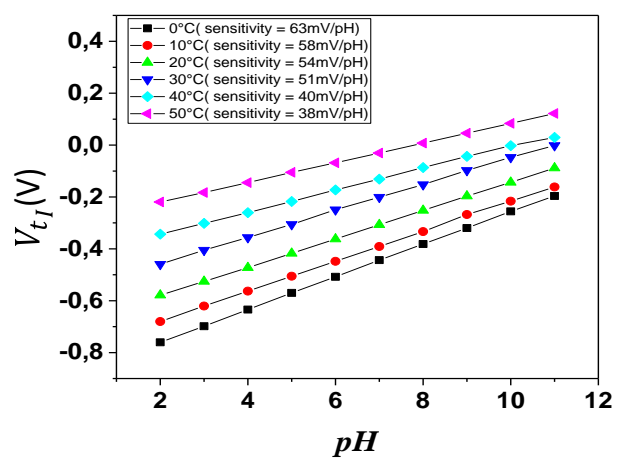

Figure 9. $\mathrm{pH}$ sensitivity of the ISFET sensor measured for a temperature from 0 to $50{ }^{\circ} \mathrm{C}$ with a step of $10^{\circ} \mathrm{C}$.

The presented data in Figure 10 were extracted from Figure 9, and present the traces of the threshold voltage for $\mathrm{pH}=6$, when the temperature varies from 0 to $50^{\circ} \mathrm{C}$. Figure 10 also illustrates the dependence of the ISFET sensor on the temperature about $10 \mathrm{mV} /{ }^{\circ} \mathrm{C}$ (nearly $20 \%$ of sensitivity is affected by temperature).

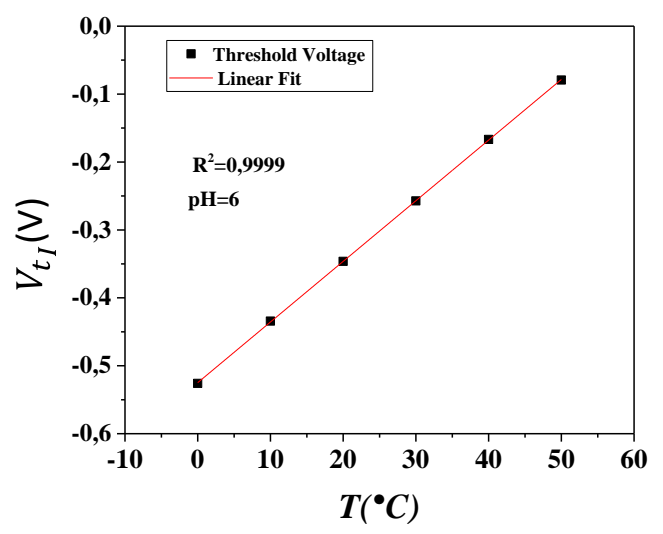

Figure 10. Threshold voltage as a function of temperature.

In cases where we have a sensor array $(6 \times 8$ ISFETs), the noise generated by the temperature can distort any measurement. Therefore, it is necessary to add a complimentary circuit in order to reduce the temperature effect. The next section presents the proposed conditioning circuit that is capable of limiting the temperature dependency of the ISFET microsensor.

\section{Proposed Temperature Compensation Circuit}

This section analyzes the conditioning circuit architecture. The differential ISFET-based $\mathrm{pH}$ measurement is shown in Figures 11 and 12. In fact, the ISFET sensor is used in a conjunction that is sensitive to a specific species (such as $\mathrm{H}^{+}$) and a reference field effect transistor (ReFET), which is insensitive to this species. ReFET was introduced to minimize the drift effects and the noise on the measurement. Both sensors must have the same electrical and chemical characteristics. A ReFET would experience a similar condition as an ISFET except the chance of responding to an occurring chemical reaction [33]. The ISFET/ReFET topology can be implemented in two configurations. The first configuration is to fabricate a REFET similar to ISFET but with a different membrane [2]. The second configuration is to make the REFET/ ISFET completely similar, but insulated and exposed to another analyst where no reaction may happen [34]. However, in addition to the DC offset problem that may bias the ISFET and REFET out of the active region causing the circuit to stack to the power-ground rail, the gate drain capacitance may distort the sensor response. The drain node is unmaintained, and it cannot follow the gate. Hence, with the Miller effects, the gain between the drain and the 
gate terminals of the deferential topology cause the appearance of the decoupling capacitors on the floating gate, and this may distort the signal. Nevertheless, to overcome the random DC offset, most of the ISFETs require a calibration of the reference electrode; ISFET/ReFET topology may also require more calibration between the ISFET and the reference FET, which makes it a little bit complicated for implementation in the ISFET arrays [2,35]. To overcome these limitations, the presented circuit in Figure 11 presents a solution for ISFET/ReFET topology. The feedback made by the amplifiers (OTA 1 and OTA 2) can control the calibration of the reference electrode to overcome the DC offset and make it easier the implementation of the ReFET/ISFET for the deferential measurement.

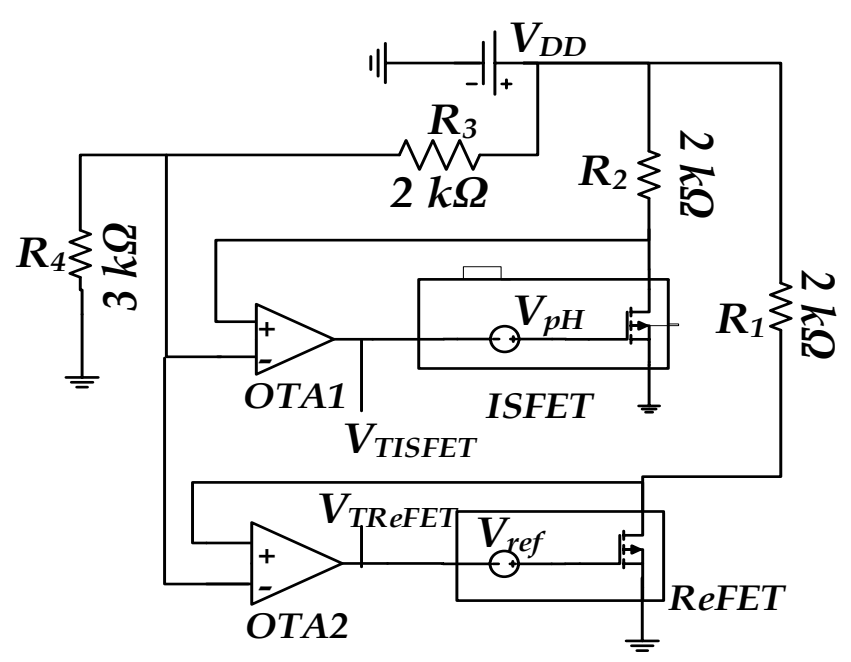

Figure 11. Differential measurement interface based on ISFET/reference field effect transistor (ReFET).
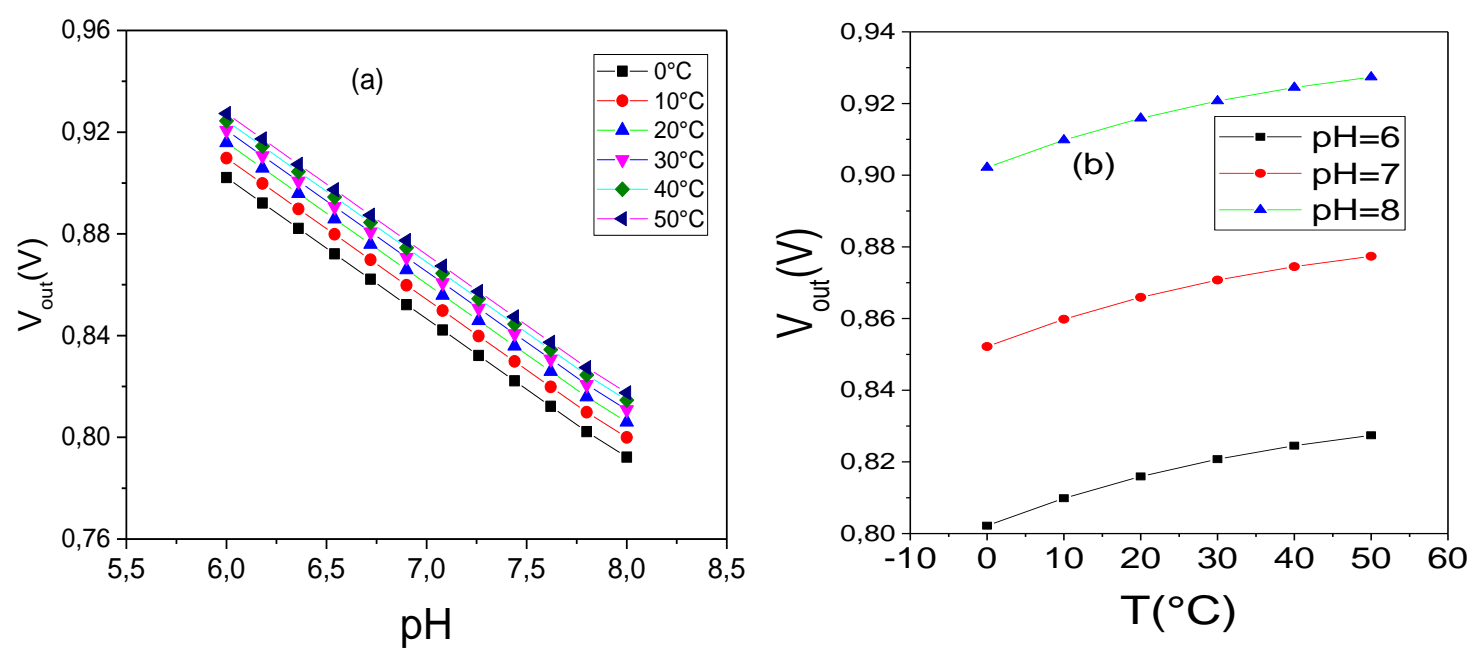

Figure 12. (a) Variation of $V_{\text {out }}$ as a function of $\mathrm{pH}$ for different temperatures, (b) variation of $V_{\text {out }}$ as a function of the temperature.

The circuit shown in Figure 11 is the one proposed by Irena [36], but the two weak power amplifier types AD8542 were replaced by the operational transconductance amplifier (OTA). The circuit was designed using ADS in TSMC $0.18 \mu \mathrm{m}$ CMOS process technology. Indeed, all the components shown in Figure 11 are temperature dependent. The power consumption for each OTA is around $8 \mu \mathrm{W}$. Thanks to the feedback made by the two OTAs, this circuit can accurately control the temperature dependence.

The voltage that is applied to the negative inputs of the amplifiers OTA1 and OTA2 is formed by the voltage divider $\left(R_{3}, R_{4}\right)$, and is written as follows:

$$
V^{-}=\frac{R 4}{R 4+R 3} V_{D D}=V_{d s} .
$$


This constant voltage $V^{-}$depends only on the power supply and is considered constant. The drain-source current $I_{d s}$ in the branch of the resistor $R_{2}$ is written as follows:

$$
I_{R 2}=I_{d s}=\frac{R_{3}}{R_{2}\left(R_{4}+R_{3}\right)} V_{D D}
$$

where $I_{d s}$ is from Equations (5) and (11), and the gate voltage of the sensor is deduced as follows:

$$
V_{g s}=\eta T \log \left(\frac{R_{3}}{I_{0} R_{2}\left(R_{4}+R_{3}\right)} V_{D D}\right)+V_{t_{I}} .
$$

We notice from Equation (12) that $V_{g s}$ varies with the threshold voltage, i.e., with the electrochemical potential of the solution $\varphi_{0}$ and the temperature. For the circuit (Figure 12), we assumed that the threshold voltage of this transistor was $V_{t_{I}}=V_{t_{I}}^{*}+V_{p H}$ with $V_{t_{I}}^{*}$ and $V_{p H}$ corresponding respectively to the theoretical threshold voltage of the transistor and the electrochemical potential of the solution. The gate voltage becomes as follows:

$$
V_{g s}=\eta T \log \left(\frac{R_{3}}{2 \eta \beta U_{T}^{2} R_{2}\left(R_{4}+R_{3}\right)} V_{D D}\right)+V_{t_{I}}^{*}+V_{p H}
$$

The DC simulation results of the circuit depicted in Figure 11 are shown in Figure 12. Figure 12a,b present respectively the variation of the output signal versus the input signal and the variation of $V_{\text {out }}\left(V_{\text {out }}=V_{T \text { ISFET }}-V_{T \text { ReFET }}\right)$ versus the temperature variation for a range from 0 to $50^{\circ} \mathrm{C}$. Indeed, the SPICE models for each component of the circuit were used, and all the components are dependent on the temperature. According to Figure 12a, the output voltage is a linear function of $p H$. This circuit has a temperature drift of approximately $2 \mathrm{mV} /{ }^{\circ} \mathrm{C}$, as shown in Figure $12 \mathrm{~b}$, where $V_{\text {out }}$ is considerably affected by the temperature. For $\mathrm{pH}$ sensitivity characterization, we worked under a $\mathrm{pH}$ range from 6 to 8 . When we chose this measurement range, we were aware that for biomedical applications such as $\mathrm{pH}$ measurement and acidity monitoring of saliva, blood, urine, and intestinal fluids, a $\mathrm{pH}$ range of 6 to 8 would be sufficient [37-39].

\subsection{Low-Power and Temperature Drift ISFET Compensation Circuit}

In order to improve immunity against temperature and increase the overall sensitivity, we propose an improvement circuit technique, which is presented in Figure 13. An instrumentation amplifier put on cascode with an inverter amplifier composes this circuit. The circuits presented in Figures 11 and 13 present two pixels in an ISFET array.

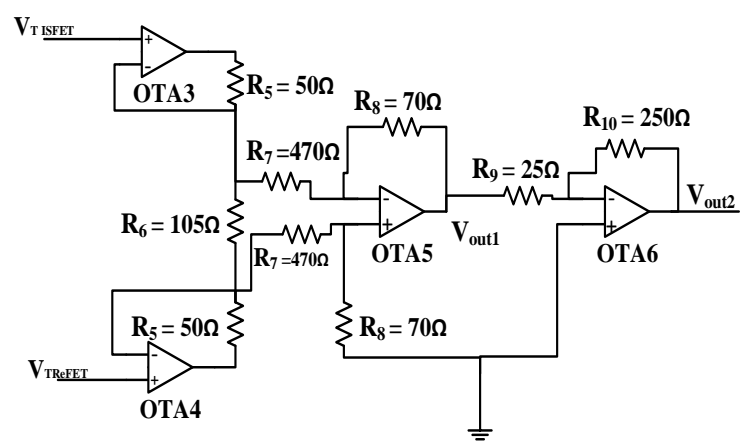

Figure 13. Operational transconductance amplifier (OTA)-based instrumentation amplifier for an ISFET temperature compensation circuit. 
The instrumentation amplifier circuit increases the immunity against the temperature by an infinite common mode rejection ratio (CMRR) [40-42]. Therefore, the output signal $V_{\text {out } 1}$ is assumed to be not affected by the common noise or temperature:

$$
V_{\text {out } 1}=\frac{R_{8}}{R_{7}}\left(1-\frac{2 R_{5}}{R_{6}}\right)\left(V_{T_{\text {ReFET }}}-V_{T_{\text {ISFET }}}\right) .
$$

As shown in Equation (14), $V_{\text {out } 1}$ is proportional to both resistance and thresholds, while the unified temperature-dependent threshold voltage of ISFET in any value can be written as follows [43]:

$$
V_{T_{(I S F E T)}}(T)_{T=T 1}=V_{T_{(p H 7)}}\left(T_{0}\right)+K V T_{(p H)}\left(T_{1}-T_{0}\right)+2.303 \frac{K T_{1}}{q} \alpha\left(p H_{p z c}-p H\right)
$$

where $\alpha$ is a coefficient with a value range between 0 and 1 . The resistance could also be expected to increase with temperature. An intuitive approach to temperature dependence leads one to expect a fractional change in the resistance that is proportional to the temperature change:

$$
R=R_{0}\left(1+\lambda\left(T_{1}-T_{0}\right)\right)
$$

where $R$ and $R_{0}$ are the resistance at temperature $T_{1}$ and $T_{0}$ (e.g., $27^{\circ} \mathrm{C}$ ), respectively. $\lambda$ stands for the temperature coefficient, which depends on the resistance material. Equation (14) becomes as follows:

$$
\begin{gathered}
V_{\text {out } 1}=\frac{R_{8}\left(1+\lambda\left(T_{1}-T_{0}\right)\right)}{R_{7}\left(1+\lambda\left(T_{1}-T_{0}\right)\right)}\left(1-\frac{2 R_{5}\left(\left(1+\lambda\left(T_{1}-T_{0}\right)\right)\right.}{R_{6}\left(1+\lambda\left(T_{1}-T_{0}\right)\right)}\right)\left(V_{T_{(p H 7)}}\left(T_{0}\right)+K V T_{(p H)}\left(T_{1}-T_{0}\right)\right. \\
+2.303 \frac{K T_{1}}{q} \alpha p H(r e f)-V_{T_{(p H 7)}}\left(T_{0}\right)-K V T_{(p H)}\left(T_{1}-T_{0}\right) \\
-2.303 \frac{K T_{1}}{q} \alpha\left(p H_{p z c}-p H\right)
\end{gathered}
$$

where $p H_{r e f}$ refers to the $\mathrm{pH}$ value measured by the ReFET. According to Equation (17) and since the ISFET and ReFET have the same technological parameters, we can neglect the $V_{T_{(p H 7)}}\left(T_{0}\right)$ and the temperature coefficient of the threshold voltage $K V T$ and assume that the resistances $R_{5}, R_{6}, R_{7}$, and $R_{8}$ have the same material; then, Equation (17) becomes:

$$
V_{\text {out } 1}=\frac{R_{8}}{R_{7}}\left(1-\frac{2 R_{5}}{R_{6}}\right) 2.303 \frac{K T_{1}}{q} \alpha\left(p H(r e f)-p H+p H_{p z c}\right) .
$$

Equation (18) illustrates the effectiveness of the proposed circuit for temperature reduction, since the two terms $K V T$ and $V_{T_{(p H 7)}}\left(T_{0}\right)$ are neglected. In addition, the thermal voltage $U_{T}=K T_{1} / q$ will always be present, because it is related to the MOSFET structure and cannot be neglected. Before the proposed circuit, the temperature coefficient of the threshold voltage $K V T$ and the $V_{T_{(p H 7)}}\left(T_{0}\right)$ significantly affect the output voltage. Then, the temperature coefficient can be obtained as follows:

$$
\left.\frac{\partial \text { Vout } 1}{\partial T}\right|_{T=T_{1}}=\frac{R_{8}}{R_{7}}\left(1-\frac{2 R_{5}}{R_{6}}\right) 2.303 \frac{K}{q} \alpha\left(p H(r e f)-p H+p H_{p z c}\right) .
$$

For $p H(r e f)=4$ and $p H_{p z c}=9.2$, Equation (19) varies between $0.23 \times 10^{-6} \mathrm{~V} /{ }^{\circ} \mathrm{C}$ and $14.03 \times 10^{-6} \mathrm{~V} /{ }^{\circ} \mathrm{C}$ for $\mathrm{pH} \in[1,13]$. Therefore, we can assume that the temperature has no significant effect on the output voltage. The estimated temperature coefficient for $\mathrm{pH}=6$ is about $9.43 \times 10^{-6} \mathrm{~V} /{ }^{\circ} \mathrm{C}$.

Figure 14a shows the variation of the output voltage $V_{\text {out } 1}$ as a function of the voltage $p H$ for different temperatures ranging from 0 to $50^{\circ} \mathrm{C}$, while Figure $14 \mathrm{~b}$ presents the dependence of $V_{\text {out } 1}$ on the temperature. Figure $14 \mathrm{~b}$ shows that a $10^{\circ} \mathrm{C}$ increase in the temperature results in a decrease of $5 \times 10^{-6} \mathrm{~V}$ of the overall system output voltage $V_{\text {out } 1}$, and subsequently, the coefficient of the temperature drift in this circuit becomes in the order of $5 \times 10^{-6} \mathrm{~V} /{ }^{\circ} \mathrm{C}$. Here, we note very well the effectiveness of the instrumentation amplifier as a function of the temperature compensation. In addition, we notice that there is concordance between the mathematical demonstration and the simulation results in terms of 
a temperature coefficient. Here, we can assume that presented the Equations (18) and (19) can predict the temperature coefficient of ISFET/ReFET topology. Hence, the variation of the output voltage cannot exploit it easily, so we added an inverter amplifier to amplify the output voltage $V_{\text {out } 1}$. Figure 15 shows the output voltage variation $V_{\text {out } 2}$ (Figure 15a) as a function of the input voltage for different temperature values.
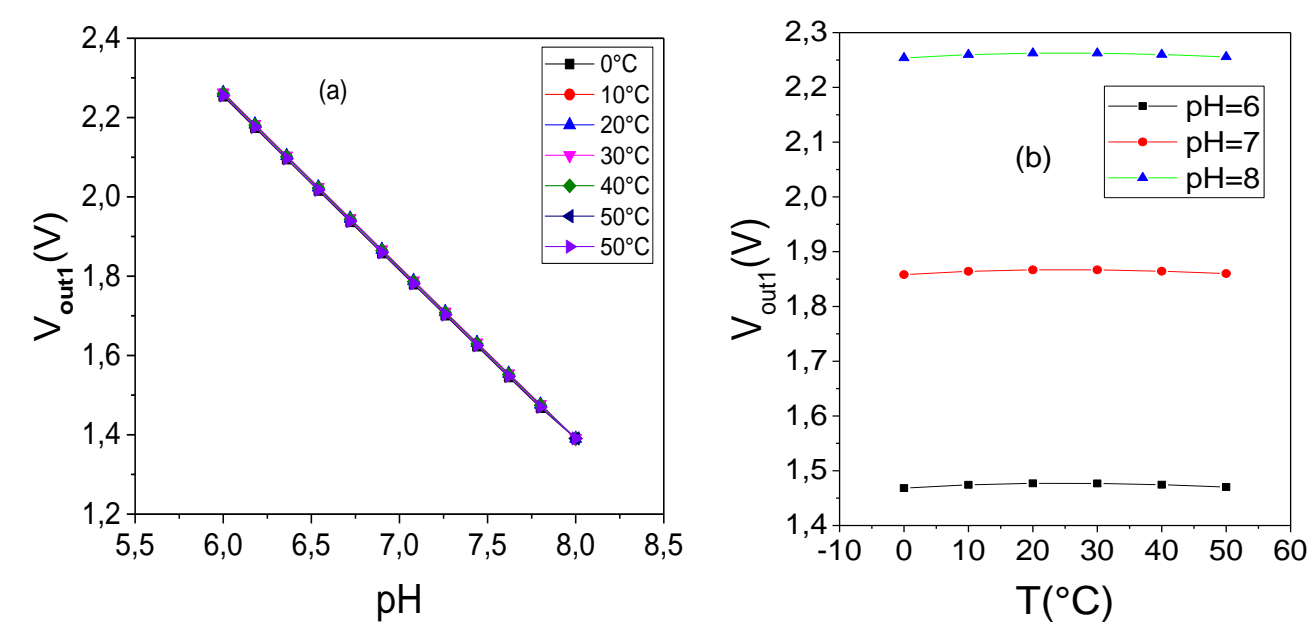

Figure 14. (a) Variation of the output voltage $V_{\text {out } 1}$ as a function of $p H$ for different temperatures, (b) variation of $V_{\text {out } 1}$ as a function of the temperature.
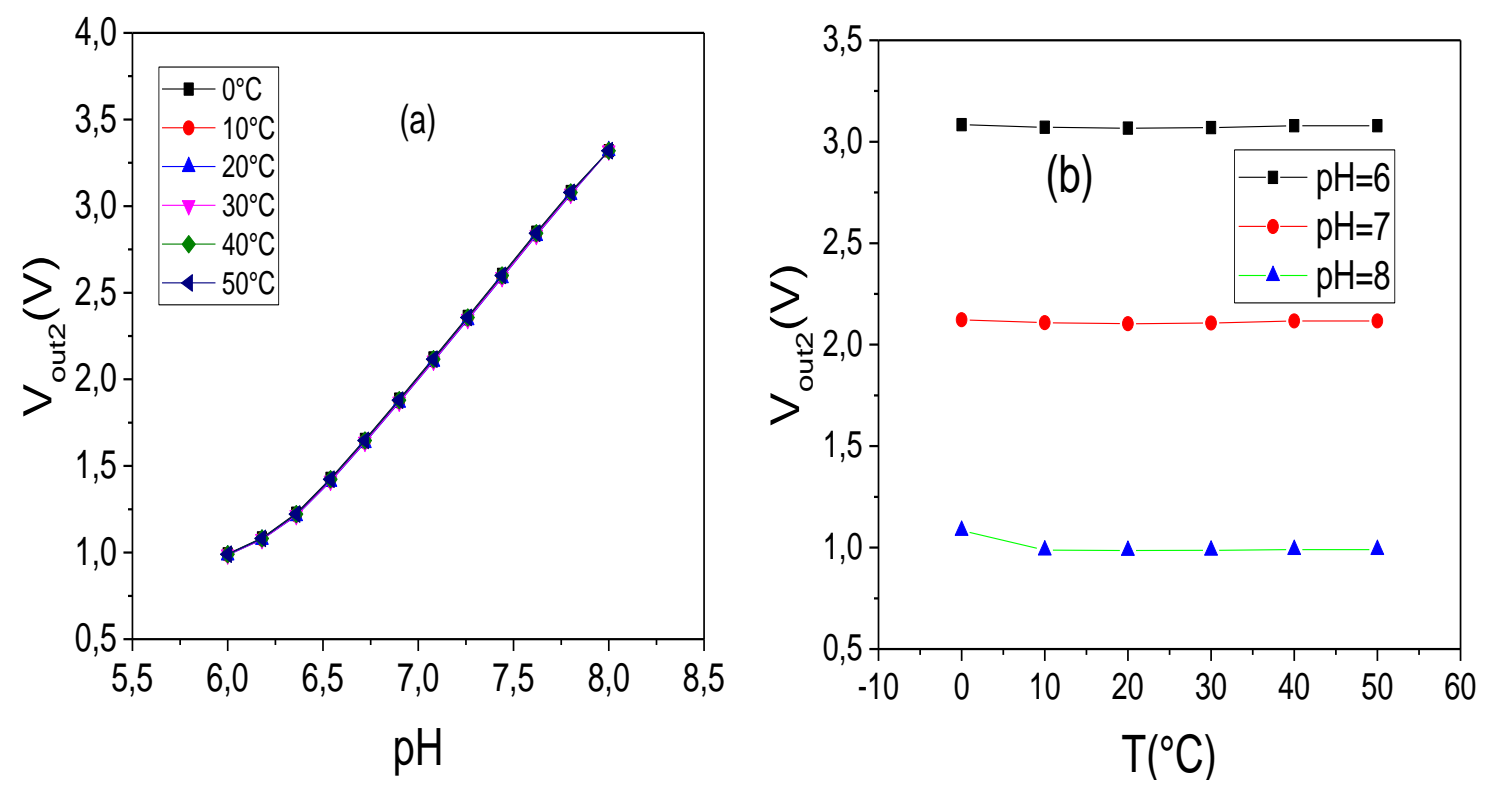

Figure 15. (a) Variation of the output voltage $V_{\text {out2 }}$ as a function of $p H$ for different temperatures, (b) variation of $V_{\text {out2 }}$ as a function of the temperature.

The resolution found in this circuit is of the order of $324 \mathrm{mV} / \mathrm{pH}$. This circuit has an in-out ratio about 6. As shown in Figure 15b, the proposed circuit has a temperature drift of about $3 \times 10^{-5} \mathrm{~V} /{ }^{\circ} \mathrm{C}$ in $\mathrm{pH}=6$ for a range of 0 to $50^{\circ} \mathrm{C}$, which is insignificant compared to the ISFET without the conditioning circuit $\left(10 \times 10^{-3} \mathrm{~V} /{ }^{\circ} \mathrm{C}\right)$. We should note that all the components of the circuit present in Figures 11 and 13 are dependent on temperature. This circuit has an estimated power consumption in the order of $1.8 \mathrm{~mW}$. 


\subsection{Discussion}

As it shows from the figures and results above that, the presented circuit undeniably represents an efficient and robust solution for biochemical reaction sensing. Target applications can include diagnostics based on DNA detection. Thanks to the possibilities for $\mathrm{H}^{+}$ion detection, this presented circuit will offer great opportunities in the field of lab-on-chip design. Table 3 compares this work with a previous work in terms of temperature compensation.

Table 3. Comparative study for temperature compensation.

\begin{tabular}{ccccc}
\hline References & {$[7]$} & {$[44]$} & {$[45]$} & This Work \\
\hline Simulator & HSPICE & Cadence & HSPICE & ADS \\
Process & MOSIS CMOS & AMS $(0.35 \mu \mathrm{m})$ & MOSIS CMOS & TSMC $(0.18 \mu \mathrm{m})$ \\
Power supply & $($ AMI $1.0 \mu \mathrm{m})$ & - & $3.3 \mathrm{~V} 1.0 \mu \mathrm{m})$ & - \\
Power consumption & $18.6(\mathrm{~mW})$ & - & - & $1.8(\mathrm{~V})$ \\
Temperature range & {$\left[20^{\circ} \mathrm{C}, 60^{\circ} \mathrm{C}\right]$} & - & {$\left[20^{\circ} \mathrm{C}, 120^{\circ} \mathrm{C}\right]$} & {$\left[0^{\circ} \mathrm{C}, 50^{\circ} \mathrm{C}\right]$} \\
Temperature coefficient & $28 \times 10^{-6}\left(\mathrm{~V} /{ }^{\circ} \mathrm{C}\right)$ & $0.25 \times 10^{-9}\left(\mathrm{~A} /{ }^{\circ} \mathrm{C}\right)$ & $23.37 \times 10^{-6}\left(\mathrm{pH} /{ }^{\circ} \mathrm{C}\right)$ & $5 \times 10^{-6}\left(\mathrm{~V} /{ }^{\circ} \mathrm{C}\right)$ \\
\hline
\end{tabular}

Table 4 presents a comparative study with other work for overall sensitivity.

Table 4. Comparative study for overall sensitivity.

\begin{tabular}{ccccc}
\hline References & {$[46]$} & {$[47]$} & {$[48]$} & This Work \\
\hline Process & $0.18 \mu \mathrm{m} \mathrm{CMOS}$ & SOI & TSMC $(65 \mathrm{~nm})$ & TSMC $(0.18 \mu \mathrm{m})$ \\
Output signal & Digital & Analog & Digital & Analog \\
Over all sensitivity $(\mathrm{mV} / \mathrm{pH})$ & 103.8 & 258 & 123.8 & 324 \\
Temperature range & - & - & - & {$\left[0{ }^{\circ} \mathrm{C}, 50^{\circ} \mathrm{C}\right]$} \\
\hline
\end{tabular}

Table 4 shows that the proposed circuit has a low temperature dependence compared to other works, and it shows that the temperature change has no significant effects on the output signal. In addition, we should note that in this work, we used ADS for the first time, and referring to Table 4, most of work used the HSPICE simulation tool. Thus, ADS will open a new perspective in signal processing for ISFET sensors. On the other hand, Table 4 illustrates the overall sensitivity; most of the published work that focused on the enhancement of the sensitivity did not focus on the temperature variation and must be addressed. Meanwhile, Tables 3 and 4 give a characteristic comparison between the proposed circuit based on OTA and others works. Using TSMC $0.18 \mu \mathrm{m}$ technology, the proposed circuit based on OTA with low power consumptions and ISFET/ReFET working in a weak inversion regime gives a robust solution to reduce the temperature dependency and enhance the overall sensitivity. The proposed circuit presents a prototype for any biosensor (MEMFET, BioFET, ChemFET).

\section{Conclusions}

The presented instrumentation with a new conditioning circuit technique has been developed to compensate for the temperature dependence and obtain a good in-out ratio of ISFET microsensors with an assurance of a low consumption. To check the validation of the new conditioning circuit, an ADS simulation of functionality for sensitivity was performed. The ADS macro model treats the ISFET as two isolated stages (an electrochemical stage and an electronic stage), which were presented. In the first step, we validated the macro model by comparing it with experimental values. Then, we investigated the temperature effect on the ISFET, and we showed that this sensor has a strong temperature dependency. After that, we used the validated macro model to develop a new circuit that is capable of staying stable at any temperature from 0 to $50{ }^{\circ} \mathrm{C}$. We also demonstrated that the proposed circuit has a good accuracy to measure the concentration of the $\mathrm{pH}$ and guaranteeing at the same time a low consumption at any temperature for a range from 0 to $50^{\circ} \mathrm{C}$. Finally, comparative studies were made in terms of the overall sensitivity. 
Author Contributions: Conceptualization, A.G. and W.D.; methodology, A.G.; software, W.D.; validation, A.G., W.D. and B.H.; formal analysis, A.G. and W.D.; investigation, M.B.A.; data curation, A.G.; writing-original draft preparation, A.G. and W.D.; writing-review and editing, A.G. and W.D.; supervision, B.H. and M.B.A. All authors have read and agreed to the published version of the manuscript.

Funding: This research received no external funding.

Conflicts of Interest: The authors declare no conflict of interest.

\section{References}

1. Bergveld, P. Development, Operation, and Application of the Ion-Sensitive Field-Effect Transistor as a Tool for Electrophysiology. IEEE Trans. Biomed. Eng. 1972, BME-19, 342-351. [CrossRef] [PubMed]

2. Bergveld, P. Thirty years of ISFETOLOGY: What happened in the past 30 years and what may happen in the next 30 years. Sens. Actuators B Chem. 2003, 88, 1-20. [CrossRef]

3. Bhardwaj, R.; Sinha, S.; Sahu, N.; Majumder, S.; Narang, P.; Mukhiya, R. Modeling and simulation of temperature drift for ISFET-based $\mathrm{pH}$ sensor and its compensation through machine learning techniques. Int. J. Circuit Theory Appl. 2019, 47, 954-970. [CrossRef]

4. Chung, W.-Y.; Lin, Y.-T.; Pijanowska, D.G.; Yang, C.-H.; Wang, M.-C.; Krzyskow, A.; Torbicz, W. New ISFET interface circuit design with temperature compensation. Microelectron. J. 2006, 37, 1105-1114. [CrossRef]

5. Liu, T.; Chung, W.; Cruz, F.R.G.; Tsai, Y.; Pijanowska, D.G.; Torbicz, W.; Grabiec, P.B.; Jaroszewicz, B. $\mathrm{V}_{\mathrm{TH}}$-Extractors Based Readout Circuit of ISFET with Temperature Compensation. In Proceedings of the 2007 IEEE Conference on Electron Devices and Solid-State Circuits, Tainan, Taiwan, 20-22 December 2007; pp. 901-904.

6. Chen, D.Y.; Chan, P.K. An Intelligent ISFET Sensory System With Temperature and Drift Compensation for Long-Term Monitoring. IEEE Sens. J. 2008, 8, 1948-1959. [CrossRef]

7. Naimi, S.E.; Hajji, B.; Humenyuk, I.; Launay, J.; Temple-Boyer, P. Temperature influence on pH-ISFET sensor operating in weak and moderate inversion regime: Model and circuitry. Sens. Actuators B Chem. 2014, 202, 1019-1027. [CrossRef]

8. Chung, W.Y.; Yang, C.H.; Pijanowska, D.G.; Grabiec, P.B.; Torbicz, W. ISFET performance enhancement by using the improved circuit techniques. Sens. Actuators B Chem. 2006, 113, 555-562. [CrossRef]

9. Liu, Y.; Al-Ahdal, A.; Georgiou, P.; Toumazou, C. Minimal readout scheme for ISFET sensing arrays based on pulse width modulation. Electron. Lett. 2012, 48, 548-549. [CrossRef]

10. Hu, Y.; Georgiou, P. An Automatic Gain Control System for ISFET Array Compensation. IEEE Trans. Circuits Syst. I Regul. Pap. 2016, 63, 1511-1520. [CrossRef]

11. Douthwaite, M.; Koutsos, E.; Yates, D.C.; Mitcheson, P.D.; Georgiou, P. A Thermally Powered ISFET Array for On-Body pH Measurement. IEEE Trans. Biomed. Circuits Syst. 2017, 11, 1324-1334. [CrossRef]

12. Huang, X.; Yu, H.; Liu, X.; Jiang, Y.; Yan, M.; Wu, D. A Dual-Mode Large-Arrayed CMOS ISFET Sensor for Accurate and High-Throughput $\mathrm{pH}$ Sensing in Biomedical Diagnosis. IEEE Trans. Biomed. Eng. 2015, 62, 2224-2233. [CrossRef] [PubMed]

13. Hu, Y.; Moser, N.; Georgiou, P. A $32 \times 32$ ISFET Chemical Sensing Array with Integrated Trapped Charge and Gain Compensation. IEEE Sens. J. 2017, 17, 5276-5284. [CrossRef]

14. Barabash, P.R.; Cobbold, R.S.C.; Wlodarski, W.B. Analysis of the threshold voltage and its temperature dependence in electrolyte-insulator-semiconductor field-effect transistors (EISFET's). IEEE Trans. Electron Devices 1987, 34, 1271-1282. [CrossRef]

15. Sardarinejad, A.; Maurya, D.K.; Khaled, M.; Alameh, K. Temperature effects on the performance of $\mathrm{RuO}_{2}$ thin-film pH sensor. Sens. Actuators A Phys. 2015, 233, 414-421. [CrossRef]

16. Hemmink, G.J.M.; Weusten, B.L.A.M.; Oors, J.; Bredenoord, A.J.; Timmer, R.; Smout, A.J.P.M. Ambulatory oesophageal pH monitoring: A comparison between antimony, ISFET, and glass $\mathrm{pH}$ electrodes. Eur. J. Gastroenterol. Hepatol. 2010, 22, 572-577. [CrossRef]

17. Moser, N.; Lande, T.S.; Toumazou, C.; Georgiou, P. ISFETs in CMOS and Emergent Trends in Instrumentation: A Review. IEEE Sens. J. 2016, 16, 6496-6514. [CrossRef]

18. Niigata, K.; Narano, K.; Maeda, Y.; Ao, J.-P. Temperature dependence of sensing characteristics of a $\mathrm{pH}$ sensor fabricated on AlGaN/GaN heterostructure. Jpn. J. Appl. Phys. 2014, 53, 11RD01. [CrossRef] 
19. Khanna, V.K. Remedial and adaptive solutions of ISFET non-ideal behaviour. Sens. Rev. 2013, 33, $228-237$. [CrossRef]

20. Bergveld, P.; Van Den Berg, A.; Van Der Wal, P.D.; Skowronska-Ptasinska, M.; Sudhölter, E.J.R.; Reinhoudt, D.N. How electrical and chemical requirements for refets may coincide. Sens. Actuators 1989, 18, 309-327. [CrossRef]

21. Errachid, A.; Bausells, J.; Jaffrezic-Renault, N. A simple REFET for pH detection in differential mode. Sens. Actuators B Chem. 1999, 60, 43-48. [CrossRef]

22. Bretschneider, F.; de Weille, J. Chapter 3-Electronic Devices. In Introduction to Electrophysiological Methods and Instrumentation, 2nd ed.; Bretschneider, F., de Weille, J., Eds.; Academic Press: Cambridge, MA, USA, 2019; pp. 39-75.

23. Morgenshtein, A.; Sudakov-Boreysha, L.; Dinnar, U.; Jakobson, C.G.; Nemirovsky, Y. Wheatstone-Bridge readout interface for ISFET/REFET applications. Sens. Actuators B Chem. 2004, 98, 18-27. [CrossRef]

24. Morgenshtein, A.; Sudakov-Boreysha, L.; Dinnar, U.; Jakobson, C.G.; Nemirovsky, Y. CMOS readout circuitry for ISFET microsystems. Sens. Actuators B Chem. 2004, 97, 122-131. [CrossRef]

25. Wong, H.; White, M.H. A CMOS-integrated 'ISFET-operational amplifier' chemical sensor employing differential sensing. IEEE Trans. Electron Devices 1989, 36, 479-487. [CrossRef]

26. Martinoia, S.; Massobrio, G. A behavioral macromodel of the ISFET in SPICE. Sens. Actuators B Chem. 2000, 62, 182-189. [CrossRef]

27. Daniel, M.; Szermer, M.; Napieralski, A.; Charlot, J.J. CHEMFET modelling for hardware description languages. In Proceedings of the Modern Problems of Radio Engineering, Telecommunications and Computer Science (IEEE Cat. No.02EX542), Lviv-Slavsko, Ukraine, 18-23 February 2002; pp. 338-341.

28. Hendji, A.M.N.; Jaffrezic-Renault, N.; Martelet, C.; Clechet, P.; Shlu'ga, A.A.; Strikha, V.I.; Netchiporuk, L.I.; Soldatkin, A.P.; Wlodarski, W.B. Sensitive detection of pesticides using a differential ISFET-based system with immobilized cholinesterases. Anal. Chim. Acta 1993, 281, 3-11. [CrossRef]

29. Ortiz-Conde, A.; García Sánchez, F.J.; Liou, J.J.; Cerdeira, A.; Estrada, M.; Yue, Y. A review of recent MOSFET threshold voltage extraction methods. Microelectron. Reliab. 2002, 42, 583-596. [CrossRef]

30. Martinoia, S.; Lorenzelli, L.; Massobrio, G.; Conci, P.; Lui, A. Temperature effects on the ISFET behaviour: Simulations and measurements. Sens. Actuators B Chem. 1998, 50, 60-68. [CrossRef]

31. Chiang, J.L.; Chou, J.C.; Chen, Y.C. Study on light and temperature properties of AlN pH-Ion-sensitive field-effect transistor devices. Jpn. J. Appl. Phys. Part 1 Regul. Pap. Short Notes Rev. Pap. 2005, 44, 4831-4837. [CrossRef]

32. Goel, A.K.; Tan, T.H. High-temperature and self-heating effects in fully depleted SOI MOSFETs. Microelectron. J. 2006, 37, 963-975. [CrossRef]

33. Mlika, R.; Ouada, H.B.; Kalfat, R.; Gamoudi, G.; Mhenni, F.; Jaffrezic-Renault, N. Thin sensitive organic membranes on selective iron-ion sensors. Synth. Met. 1997, 90, 239-243. [CrossRef]

34. Garner, D.M.; Bai, H.; Georgiou, P.; Constandinou, T.G.; Reed, S.; Shepherd, L.M.; Wong, W.; Lim, K.T.; Toumazou, C. A multichannel DNA SoC for rapid point-of-care gene detection. In Proceedings of the 2010 IEEE International Solid-State Circuits Conference (ISSCC), San Francisco, CA, USA, 7-11 February 2010; pp. 492-493.

35. Sohbati, M. Circuits and Systems for DNA Detection by Ion-Sensitive Field Effect Transistor. Ph.D. Thesis, Imperial College London, London, UK, 2014.

36. Humenyuk, I. Développement des Microcapteurs ChemFETs Pour L'analyse de L'eau. Ph.D. Thesis, Institut National des Sciences Appliquées de Toulouse, Toulouse, France, 2005.

37. Mellins, R.B.; Levine, O.R.; Wigger, H.J.; Leidy, G.; Curnen, E.C. Experimental menigococcemia: Model of overwhelming infection in unanesthetized monkeys. J. Appl. Physiol. 1972, 32, 309-314. [CrossRef] [PubMed]

38. Evans, D.F.; Pye, G.; Bramley, R.; Clark, A.G.; Dyson, T.J.; Hardcastle, J.D. Measurement of gastrointestinal pH profiles in normal ambulant human subjects. Gut 1988, 29, 1035. [CrossRef] [PubMed]

39. Baliga, S.; Muglikar, S.; Kale, R. Salivary pH: A diagnostic biomarker. J. Indian Soc. Periodontol. 2013, 17, 461-465. [CrossRef] [PubMed]

40. Safari, L.; Minaei, S. A novel COA-based electronically adjustable current-mode instrumentation amplifier topology. AEU Int. J. Electron. Commun. 2017, 82, 285-293. [CrossRef]

41. Eldeeb, M.A.; Ghallab, Y.H.; Ismail, Y.; El-Ghitani, H. A 0.4-V Miniature CMOS Current Mode Instrumentation Amplifier. IEEE Trans. Circuits Syst. II Express Briefs 2018, 65, 261-265. [CrossRef] 
42. Butti, F.; Piotto, M.; Bruschi, P. A Chopper Instrumentation Amplifier With Input Resistance Boosting by Means of Synchronous Dynamic Element Matching. IEEE Trans. Circuits Syst. I Regul. Pap. 2017, 64, 753-764. [CrossRef]

43. Chan, P.K.; Chen, D.Y. A CMOS ISFET interface circuit with dynamic current temperature compensation technique. IEEE Trans. Circuits Syst. I Regul. Pap. 2007, 54, 119-129. [CrossRef]

44. Ma, D.; Georgiou, P.; Toumazou, C. A weak inversion ISFET current mirror for differential bio-sensing. In Proceedings of the 2016 IEEE Biomedical Circuits and Systems Conference (BioCAS), Shanghai, China, 17-19 October 2016; pp. 42-45.

45. Harrak, A.; Naimi, S.E. Design and simulation of a CMOS compatible pH-ISFET readout circuit, with low thermal sensitivity. In Proceedings of the 2017 International Conference on Electrical and Information Technologies (ICEIT), Rabat, Morocco, 15-18 November 2017; pp. 1-6.

46. Xiwei, H.; Fei, W.; Jing, G.; Mei, Y.; Hao, Y.; Kiat Seng, Y. A $64 \times 641200$ fps CMOS ion-image sensor with suppressed fixed-pattern-noise for accurate high-throughput DNA sequencing. In Proceedings of the 2014 Symposium on VLSI Circuits Digest of Technical Papers, Honolulu, HI, USA, 10-13 June 2014; pp. 1-2.

47. Park, J.-K.; Jang, H.-J.; Park, J.-T.; Cho, W.-J. SOI dual-gate ISFET with variable oxide capacitance and channel thickness. Solid State Electron. 2014, 97, 2-7. [CrossRef]

48. Jiang, Y.; Liu, X.; Dang, T.C.; Huang, X.; Feng, H.; Zhang, Q.; Yu, H. A High-Sensitivity Potentiometric 65-nm CMOS ISFET Sensor for Rapid E. coli Screening. IEEE Trans. Biomed. Circuits Syst. 2018, 12, 402-415. [CrossRef]

(C) 2020 by the authors. Licensee MDPI, Basel, Switzerland. This article is an open access article distributed under the terms and conditions of the Creative Commons Attribution (CC BY) license (http://creativecommons.org/licenses/by/4.0/). 